\title{
Presynaptic Calcium Influx Controls Neurotransmitter Release in Part by Regulating the Effective Size of the Readily Releasable Pool
}

\author{
Monica S. Thanawala and Wade G. Regehr \\ Department of Neurobiology, Harvard Medical School, Boston MA 02115
}

The steep calcium dependence of synaptic strength that has been observed at many synapses is thought to reflect a calcium dependence of the probability of vesicular exocytosis $(p)$, with the cooperativity of three to six corresponding to the multiple calcium ion binding sites on the calcium sensor responsible for exocytosis. Here we test the hypothesis that the calcium dependence of the effective size of the readily releasable pool (RRP) also contributes to the calcium dependence of release at the calyx of Held synapse in mice. Using two established methods of quantifying neurotransmitter release evoked by action potentials (effective RRP), we find that when calcium influx is changed by altering the external calcium concentration, the calcium cooperativity of $p$ is insufficient to account for the full calcium dependence of EPSC size; the calcium dependence of the RRP size also contributes. Reducing calcium influx by blocking R-type voltage-gated calcium channels (VGCCs) with $\mathrm{Ni}^{2+}$, or by blocking P/Q-type VGCCs with $\omega$-agatoxin IVA also changes EPSC amplitude by reducing both $p$ and the effective RRP size. This suggests that the effective RRP size is dependent on calcium influx through VGCCs. Furthermore, activation of $\mathrm{GABA}_{\mathrm{B}}$ receptors, which reduces presynaptic calcium through VGCCs without other significant effects on release, also reduces the effective RRP size in addition to reducing $p$. These findings indicate that calcium influx regulates the RRP size along with $p$, which contributes to the calcium dependence of synaptic strength, and it influences the manner in which presynaptic modulation of presynaptic calcium channels affects neurotransmitter release.

\section{Introduction}

Fundamental to our understanding of synaptic transmission is the calcium dependence of neurotransmitter release. First seen at the frog neuromuscular junction (Jenkinson, 1957; Dodge and Rahamimoff, 1967), a steep dependence on calcium ( $n=3-6)$ has subsequently been observed at many synapses for postsynaptic currents evoked by action potentials, local application of $\mathrm{Ca}^{2+}$, photolysis of caged calcium, and presynaptic voltage steps (Smith et al., 1985; Wu and Saggau, 1994; Mintz et al., 1995; Borst and Sakmann, 1996; Schneggenburger and Neher, 2000). The calcium cooperativity of release is widely appreciated as arising from cooperative binding of calcium to the calcium sensor responsible for vesicular fusion, which increases the probability of release $(p)$ (Augustine, 2001).

But do changes in calcium influx affect synaptic transmission exclusively through $p$, or does another calcium-dependent process also play a role? It is also possible that changes in the size of the readily releasable pool (RRP), defined as the number of syn-

\footnotetext{
Received Aug. 22, 2012; revised Dec. 12, 2012; accepted Dec. 19, 2012.

Author contributions: M.S.T. and W.G.R. designed research; M.S.T. performed research; M.S.T. and W.G.R. analyzed data; M.S.T. and W.G.R. wrote the paper.

This work was supported by National Institutes of Health (NIH) Grant R37 NS032405 to W.G.R. and NIH Grant F31 NS073252 to M.S.T. We thank Miklos Antal, YunXiang Chu, Diasynou Fioravante, Lindsey Glickfeld, Court Hull, Skyler Jackman, and Todd Pressler for comments on a previous version of this manuscript.

Correspondence should be addressed to Wade G. Regehr, Goldenson 308, Department of Neurobiology, Harvard Medical School, 220 Longwood Avenue, Boston, MA 02115. E-mail: wade_regehr@hms.harvard.edu.

DOI:10.1523/JNEUROSCI.4031-12.2013

Copyright $\odot 2013$ the authors $\quad 0270-6474 / 13 / 334625-09 \$ 15.00 / 0$
}

aptic vesicles accessible for release by an action potential (Rizzoli and Betz, 2005), could contribute. Previous studies have used high-frequency stimulus trains to deplete the RRP and observed an increase in the cumulative EPSC in elevated external calcium $\left(\mathrm{Ca}_{\mathrm{e}}\right)$ (Schneggenburger et al., 1999; Lou et al., 2008). They attributed these observations to incomplete depletion in standard $\mathrm{Ca}_{\mathrm{e}}$, because the size of the RRP determined by a prolonged voltage step is not $\mathrm{Ca}_{\mathrm{e}}$ dependent. These findings did, however, suggest that the size of the effective RRP, which we will define as the vesicles liberated by high-frequency stimulation, is $\mathrm{Ca}_{\mathrm{e}}$ dependent.

Here, we argue that changes in the effective RRP size are significant, and that the extent of presynaptic calcium influx may be crucial to determine the size of the effective RRP. Unlike presynaptic voltage steps and photolysis of caged calcium, action potentials provide a very brief local increase in free calcium ions. It is possible that action potentials cannot access the entirety of the $\mathrm{RRP}$, and that the concept of an effective RRP is important in studies of synaptic transmission. If the size of the effective RRP is calcium dependent, then changes in $p$ would not fully explain changes in synaptic strength. In addition to being important for a mechanistic understanding of synaptic transmission, the relative contributions of $p$ and RRP have functional implications: changes in $p$ affect short-term plasticity but do not alter total vesicle fusion evoked by a train, whereas changes in RRP do not affect short-term plasticity but do alter total release.

In this study, we characterize the calcium dependence of EPSC amplitude, $p$, and the effective RRP at the calyx of Held synapse. We 
find that the calcium dependence of $p$ is insufficient to account for the calcium dependence of the EPSC size, and that the effective RRP size is calcium dependent. Our experiments indicate that neuromodulators that regulate presynaptic voltage-gated calcium channels (VGCCs) regulate both $p$ and effective RRP size. These results can have important implications for understanding how synaptic transmission is regulated, especially in response to high-frequency activity as typically occurs at this synapse.

\section{Materials and Methods}

Animals and preparation of brain slices. All animals used were wild-type mice (BL6C57/6J, The Jackson Laboratory) postnatal day 11-14 of either sex. All animal handling and procedures abided by the guidelines of the Harvard Medical Area Standing Committee on Animals. Mice were deeply anesthetized with isoflurane and killed by decapitation. Transverse $200-\mu \mathrm{m}$-thick slices were cut from the brainstem containing the medial nucleus of the trapezoid body (MNTB) with a vibratome slicer. Brains were dissected and sliced at $4^{\circ} \mathrm{C}$ in a solution consisting of the following (in mM): $125 \mathrm{NaCl}, 25 \mathrm{NaHCO}_{3}, 1.25 \mathrm{NaH}_{2} \mathrm{PO}_{4}, 2.5 \mathrm{KCl}, 0.1$ $\mathrm{CaCl}_{2}, 3 \mathrm{MgCl}_{2}, 25$ glucose, 3 myo-inositol, $2 \mathrm{Na}$-pyruvate, and 0.4 ascorbic acid, continuously bubbled with $95 \% \mathrm{O}_{2} / 5 \% \mathrm{CO}_{2}$, pH 7.4. Slices were incubated at $32^{\circ} \mathrm{C}$ for $20 \mathrm{~min}$ in a bicarbonate-buffered solution composed of the following (in mM): $125 \mathrm{NaCl}, 25 \mathrm{NaHCO}_{3}, 1.25$ $\mathrm{NaH}_{2} \mathrm{PO}_{4}, 2.5 \mathrm{KCl}, 2 \mathrm{CaCl}_{2}, 1 \mathrm{MgCl}_{2}, 25$ glucose, 3 myo-inositol, 2 Na-pyruvate, and 0.4 ascorbic acid, continuously bubbled with $95 \%$ $\mathrm{O}_{2} / 5 \% \mathrm{CO}_{2}, \mathrm{pH}$ 7.4. For experiments in Figure 3, slices were incubated in a solution similar to that above but with varying $\mathrm{CaCl}_{2}$ and $\mathrm{MgCl}_{2}$ to accommodate future experiments. The concentration of $\mathrm{CaCl}_{2}$ plus that of $\mathrm{MgCl}_{2}$ was always equal to $3 \mathrm{~mm}$ when $\mathrm{Ca}_{\mathrm{e}} \leq 2 \mathrm{~mm}$. For experiments with $\mathrm{Ca}_{\mathrm{e}}=3$ and $4 \mathrm{~mm},\left[\mathrm{Mg}^{2+}\right]=0.1 \mathrm{~mm}$.

Electrophysiology. Slices were transferred to a recording chamber at room temperature. During recordings, the standard perfusion solution consisted of the bicarbonate-buffered solution (see above) with $1 \mu \mathrm{M}$ strychnine and $25 \mu \mathrm{M}$ bicuculline to block inhibitory synaptic transmission. Then $1 \mathrm{~mm}$ kynurenic acid and $0.1 \mathrm{~mm}$ cyclothiazide (Tocris Bioscience/R\&D Systems) were also added to block AMPA receptor saturation and desensitization, respectively. Slices were superfused at 1-3 $\mathrm{ml} / \mathrm{min}$ with this external solution. Whole-cell postsynaptic patch-clamp recordings were made from visually identified cells in the MNTB region using glass pipettes of 2-3 $\mathrm{M} \Omega$ resistance, filled with an internal recording solution consisting of the following (in $\mathrm{mm}$ ): $110 \mathrm{CsCl}, 35 \mathrm{CsF}, 10$ EGTA, 10 HEPES, and 2 QX-314, pH 7.2, 315-320 mOsm. Series resistance $\left(\mathrm{R}_{\mathrm{s}}\right)$ was compensated by up to $60 \%$ and the membrane potential was held at $-60 \mathrm{mV}$. EPSCs were evoked by stimulating presynaptic axons with a bipolar stimulating electrode placed midway between the medial border of the MNTB and the midline of the brainstem. A Multiclamp 700A (Axon Instruments/Molecular Devices) amplifier was used. Recordings were digitized at $20 \mathrm{kHz}$ with an ITC-18 A/D converter (Instrutech) using custom procedures (written by M.A. Xu-Friedman) in IgorPro (Wavemetrics) and filtered at $8 \mathrm{kHz}$. Access resistance and leak current were monitored and experiments were rejected if either parameter changed significantly. Recordings were performed at room temperature $\left(25^{\circ} \mathrm{C}\right)$ in Figures $1-6$ and $8 B$ and at $35^{\circ} \mathrm{C}$ in Figures 7 and $8 \mathrm{C}$.

Data analysis. The effective size of the RRP was calculated using two techniques. To measure $\mathrm{RRP}_{\text {train }}$, a measure of effective RRP size, peak EPSC amplitudes are measured and summed. A straight line was fitted to the final 15 points of the cumulative EPSC and back-extrapolated to the $y$-axis. The $y$-intercept corresponds to $\mathrm{RRP}_{\text {train }}$, and $p_{\text {train }}$ equals $\mathrm{EPSC}_{0}$ divided by $\mathrm{RRP}_{\text {train, }}$ as previously described (Schneggenburger et al., 1999). $\mathrm{RRP}_{\text {train }}^{\mathrm{COR}}$, a corrected version of $\mathrm{RRP}_{\text {train }}$, is measured by backextrapolating to the $y$-axis with a curve instead of a straight line. The derivative of the curve is calculated by normalizing the peak EPSC amplitudes to the largest EPSC and subtracting each from 1. We then take the integral of this to get the summed capacity for replenishment (availability of empty sites) over the time elapsed from the beginning of the train. The resulting curve is scaled such that the final 15 points of the curve matches those of the cumulative EPSC. This process computes the RRP with a replenishment rate proportional to the number of empty sites available for new vesicles. $p_{\text {train }}^{\mathrm{COR}}$ was calculated as $\mathrm{EPSC}_{0}$ divided by $\mathrm{RRP}_{\text {train }}^{\mathrm{COR}}$.

To measure $\mathrm{RRP}_{\mathrm{EQ}}$, another measure of effective RRP size (Elmqvist and Quastel, 1965), peak EPSC amplitudes were plotted versus the cumulative EPSC. A line was fitted to the steepest range of this curve. We used four points for $100 \mathrm{~Hz}$ trains delivered at $25^{\circ} \mathrm{C}$ and three points for $300 \mathrm{~Hz}$ trains delivered at $35^{\circ} \mathrm{C}$ due to more rapid depletion. The $x$-intercept of this line corresponds to $\mathrm{RRP}_{\mathrm{EQ}} \cdot p_{\mathrm{EQ}}$ equals $\mathrm{EPSC}_{0}$ divided by $\mathrm{RRP}_{\mathrm{EQ}}$.

Data analysis was performed using routines written in IgorPro. Curve fitting was performed using a curve fitting application in IgorPro. Pairwise comparisons were performed with one-tailed Student's paired $t$ tests. The level of significance was set at $p<0.05$.

Simulations. Simple simulations were used to describe the effect of changing $p$, effective RRP, or both on the response to a $100 \mathrm{~Hz}$ train (Fig. 8). In the absence of recovery from depression (Fig. 8A), EPSC amplitudes are the product of the number of vesicles remaining in the effective RRP (number of vesicles multiplied by quantal current) and $p$ as follows:

$$
\operatorname{EPSC}_{n}=p N_{o}(1-p)^{n}
$$

When there is recovery proportional to the number of empty sites (Fig. $8 B, C)$ :

$$
E P S C_{1}=\operatorname{EPSC}_{0}(1-p+p R),
$$

where $R$ is a constant that accounts for recovery. For $n>1$, if there are $X_{n}$ sites occupied prior to stimulus $n$, and $Y_{n}$ sites occupied immediately after stimulus $n$ ( $Y_{n}$ and $X_{n}$ are normalized to the total number of sites, $N_{0}$ ), then:

$$
\begin{gathered}
X_{n}=Y_{n-1}+R\left(1-Y_{n-1}\right) \\
X_{n}=Y_{n-1}(1-R)+R \\
Y_{n}=(1-p) X_{n} \\
X_{n}=(1-p) X_{n-1}+R\left[1-(1-p) X_{n-1}\right] \\
X_{n}=(1-p)(1-R) X_{n-1}+R
\end{gathered}
$$

The amplitude of the EPSC evoked by stimulus $n$ is:

$$
\begin{gathered}
\operatorname{EPSC}_{n}=p N_{0} X_{n} \\
\operatorname{EPSC}_{n}=\operatorname{EPSC}_{n-1}(1-p)(1-R)+p N_{0} R
\end{gathered}
$$

The replenishment rate $(R)$ is proportional to the extent of depletion, which is consistent with the experimentally determined properties of recovery from depression (see Fig. $2 E$ ). We achieve this in the model by assuming that the replenishment rate is proportional to the number of empty release sites available for newly docked vesicles (assume constant replenishment per empty release site). The replenishment rate throughout the train is a fraction of the maximal rate. The fraction is equal to the number of available sites open for replenishment. At $t=0$, the RRP is assumed to be full (number of available release sites is zero).

\section{Results}

We initially studied the effect of altering calcium influx on synaptic transmission at the calyx of Held synapse by altering external calcium $\left(\mathrm{Ca}_{\mathrm{e}}\right)$. Experiments were performed in the presence of kynurenate $(1 \mathrm{mM})$ and cyclothiazide $(100 \mu \mathrm{M})$ to block AMPA receptor saturation and desensitization, respectively. Presynaptic axons were stimulated with a bipolar electrode to evoke postsynaptic responses with pairs of pulses (interstimulus interval $=10$ $\mathrm{ms}$ ) every $10 \mathrm{~s}$ to assess EPSC amplitude and the paired-pulse ratio. Periodically, a high-frequency train $(40$ stimuli at $100 \mathrm{~Hz}$ ) was delivered to deplete the effective RRP. A $100 \mathrm{~Hz}$ train was used because it is within the physiological range and reliably evokes postsynaptic responses under our recording conditions.

As expected, the EPSC amplitude was strongly enhanced in 2 $\mathrm{mM} \mathrm{Ca}_{\mathrm{e}}$ as compared with $1.25 \mathrm{mM} \mathrm{Ca}_{\mathrm{e}}$ (Fig. $1 A$ ) and there was a 
A

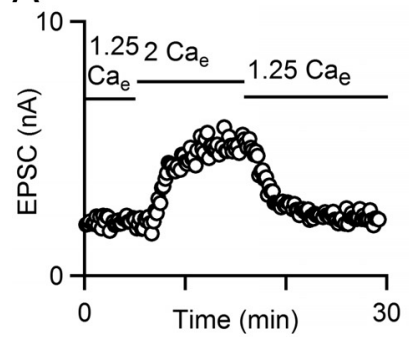

C

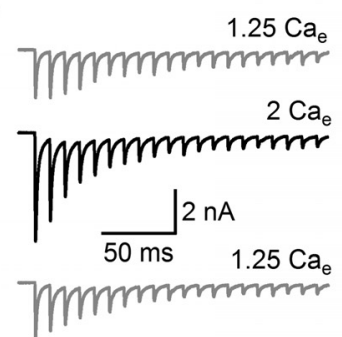

E

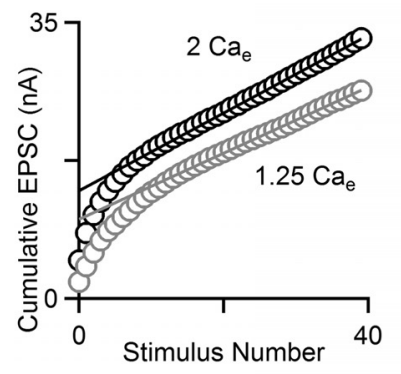

B
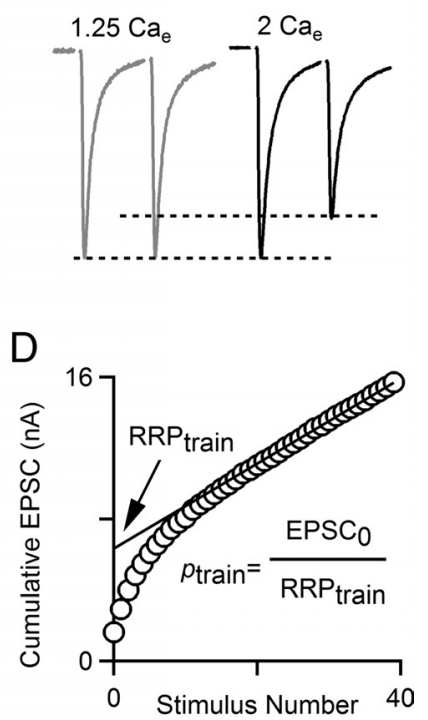

$\mathrm{F}$

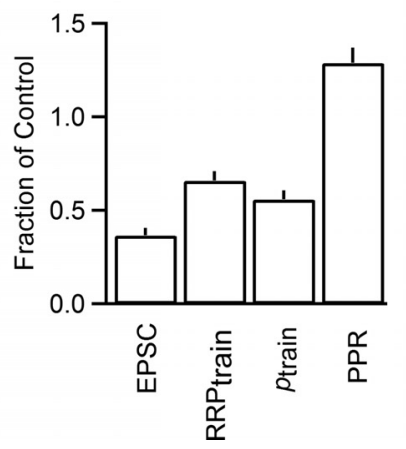

Figure 1. Altering presynaptic calcium influx affects synaptic transmission in part by changing effective RRP size. $A$, Time course of EPSC amplitude during wash-in of $2 \mathrm{~mm}$ external calcium $\left(\mathrm{Ca}_{\mathrm{e}}\right)$, followed by $1.25 \mathrm{~mm} \mathrm{Ca}_{\mathrm{e}} \cdot \boldsymbol{B}, \mathrm{A}$ comparison of pairs of EPSCs normalized to the amplitude of the first EPSC (EPSC $)$ reveals that paired-pulse plasticity varies with $\mathrm{Ca}_{\mathrm{e}}$. C, EPSCS evoked by $100 \mathrm{~Hz}$ trains delivered in different $\mathrm{Ca}_{\mathrm{e}}$ conditions. $\boldsymbol{D}$, Example estimation of effective RRP size $\left(R_{R P}\right.$ train $)$ by back-extrapolation of the cumulative EPSC to the $y$-axis. The probability of release ( $\left.p_{\text {train }}\right)$ is estimated by dividing the amplitude of the first EPSC by RRP train $E$, A comparison of cumulative EPSCs reveals that RRP train is larger in $2 \mathrm{~mm} \mathrm{Ca}_{\mathrm{e}}$ than in $1.25 \mathrm{~mm} \mathrm{Ca}$. $\boldsymbol{F}$, Summary of the effects of altered $\mathrm{Ca}_{\mathrm{e}}(1.25 \mathrm{~mm}$ compared with $2 \mathrm{~mm}$ in control) on the properties of synaptic transmission $(n=5)$.

decrease in the paired-pulse ratio (Fig. $1 B$ ) that typically accompanies an increase in the probability of release $(p)$. Trains were delivered in $1.25 \mathrm{~mm}$ external calcium $\left(\mathrm{Ca}_{\mathrm{e}}\right)$ and $2 \mathrm{~mm} \mathrm{Ca}_{\mathrm{e}}$ and postsynaptic responses recorded (Fig. 1C). The first EPSCs were considerably larger in $2 \mathrm{mM} \mathrm{Ca}_{\mathrm{e}}$ than in $1.25 \mathrm{mM} \mathrm{Ca}_{\mathrm{e}}$, but responses in both conditions decayed to a similar steady-state EPSC amplitude late in the train. An example in Figure $1 D$ illustrates an approach that is widely used to estimate the effective size of the RRP that is released by a train. Peak EPSC amplitudes are summed and plotted versus stimulus number. The RRP is thought to be depleted early in the train, such that the steady-state EPSC amplitude late in the train reflects replenishment of the RRP. The rate of replenishment is assumed to be constant and accounted for by back-extrapolating a line from the final 15 points of the cumulative EPSC to the $y$-axis. The $y$-intercept corresponds to the number of vesicles in the RRP multiplied by the quantal size $(\mathrm{Nq})$ and is called $\mathrm{RRP}_{\text {train }}$. This technique was first used at the calyx of Held but has subsequently been applied at a variety of synapses (Schneggenburger et al., 1999; Moulder and

Mennerick, 2005; Stevens and Williams, 2007; Pan and Zucker, $2009)$. The probability of release $\left(p_{\text {train }}\right)$ can be estimated by dividing the amplitude of the first EPSC $\left(\mathrm{EPSC}_{0}\right)$ by $\mathrm{RRP}_{\text {train }}$. This method reveals that $\mathrm{RRP}_{\text {train }}$ is reduced in $1.25 \mathrm{mM} \mathrm{Ca}_{\mathrm{e}}$ as compared with $2 \mathrm{mM} \mathrm{Ca}_{\mathrm{e}}$ (Fig. $1 E$ ). Based on the method of Figure $1 D$, the reduction of EPSC amplitude in $1.25 \mathrm{mM} \mathrm{Ca}_{\mathrm{e}}(36.7 \pm 4.1 \%$ of control, $p<0.01)$ is a result of reduced effective pool size $\left(\mathrm{RRP}_{\text {train }}\right.$; $65.9 \pm 5.1 \%$ of control, $p<0.05)$ and reduced release probability ( $p_{\text {train }} ; 55.8 \pm 4.7 \%$ of control, $p<0.01$ ). The reduction in release probability is also indicated by an increase in PPR (Fig. $1 F$ ).

The results of Figure 1 suggest that alterations in calcium influx change neurotransmitter release in part by changing the effective pool size. It is, however, important to recognize that quantification of the RRP can be controversial, and each method used to quantify the RRP relies on assumptions about release. For example, the train method of Figure 1 assumes that the rate of replenishment from the reserve pool to the RRP is constant during a train. We therefore decided to use an additional method to quantify the amount of neurotransmitter released by a highfrequency train, a method previously developed for use at the frog neuromuscular junction (Elmqvist and Quastel, 1965) and subsequently used at the calyx of Held synapse (Taschenberger et al., 2005; Kushmerick et al., 2006). This method assumes that for a high- $p$, depressing synapse, depletion of the RRP dominates the amplitude of the synaptic responses early in a high-frequency train. In an example cell in control conditions $\left(2 \mathrm{mM} \mathrm{Ca}_{\mathrm{e}}\right)$, synaptic responses depress quickly during the first 5 to 10 stimuli of a $100 \mathrm{~Hz}$ train, following a decaying single-exponential curve (Fig. 2A). A plot of EPSC amplitudes versus the cumulative EPSC transforms the first few responses, which serve to almost completely deplete the RRP, to follow a straight line. This line can be extrapolated to intersect the $x$-axis (Fig. 2B). The $x$-intercept corresponds to the size of the $R R P\left(R R P_{E Q}\right)$ assuming no replenishment of the RRP during the first few stimuli. Since there will be some replenishment of the RRP during the first $\sim 50 \mathrm{~ms}$ of the train, $\mathrm{RRP}_{\mathrm{EQ}}$ will overestimate the size of the RRP and can be considered an upper-bound estimate of RRP size. This contrasts with the $\mathrm{RRP}_{\text {train }}$ approach, which assumes a constant rate of replenishment equal to that of the end of the train, when in fact the rate of replenishment likely increases during the train, and therefore $\mathrm{RRP}_{\text {train }}$ provides a lower-bound estimate of the RRP. Thus, two entirely different methods can be used to estimate the size of the RRP for stimulus trains; each method relies on its own set of assumptions, and one method provides a lower bound for RRP while the other provides an upper bound.

We therefore compared our estimates of RRP by plotting $\mathrm{RRP}_{\text {train }}$ versus $\mathrm{RRP}_{\mathrm{EQ}}$ for cells in different $\mathrm{Ca}_{\mathrm{e}}$ (between 1 and 4 $\mathrm{mM}$ ), and found that as expected, $\mathrm{RRP}_{\mathrm{EQ}}$ was typically greater than $\mathrm{RRP}_{\text {train }}$ (Fig. 2C). This is apparent by comparing the fit to the data (Fig. $2 C$, solid line, slope $(m)=0.751, y$-intercept $(b)=$ $0.72 \mathrm{nA}$ ) with the unity line (Fig. $2 C$, dashed line). Accordingly, estimates of $p$ from $\mathrm{RRP}_{\mathrm{EQ}}\left(p_{\mathrm{EQ}}\right)$ were typically smaller than $p_{\text {train }}$ (Fig. 2D), which was again apparent by comparing the fit to the data (Fig. $2 D$, solid line, $m=0.957, b=0.061$ ) with the unity line (Fig. $2 D$, dashed line). It appears that although $\mathrm{RRP}_{\text {train }}$ is generally slightly smaller than $\mathrm{RRP}_{\mathrm{EQ}}$, these two methods provide similar estimates of RRP and do a good job of bracketing the effective RRP. To resolve the differences in pool sizes measured by these two techniques, we tested the validity of the assumption of constant recovery from depression early and late in the train. There are two potential reasons for increased recovery from depression during the train. First, the number of vesicles added to the RRP between stimuli is probably low at the beginning of the train due 
A

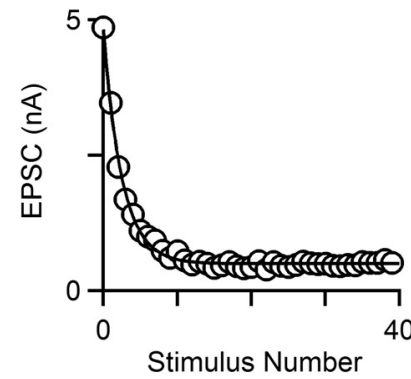

C

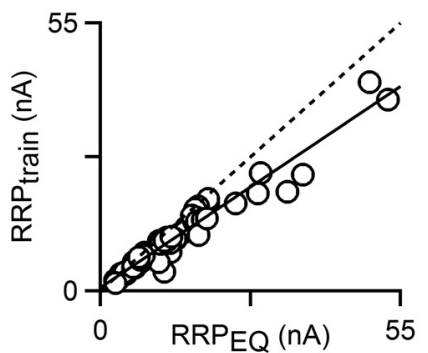

E

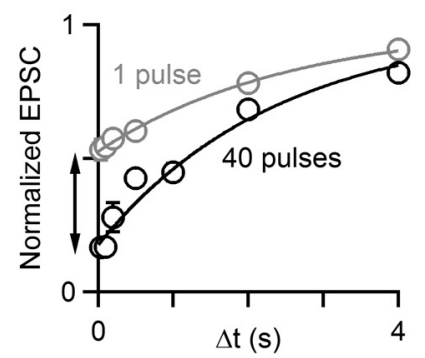

G

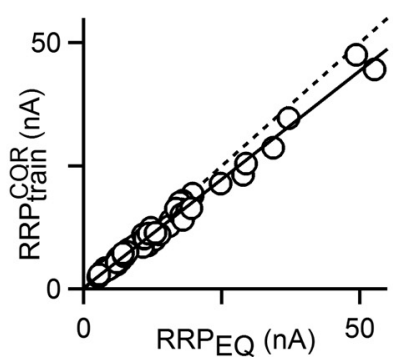

B

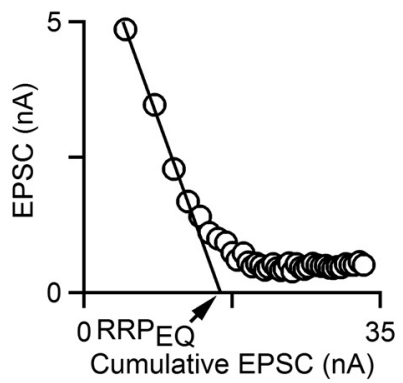

$\mathrm{D}$

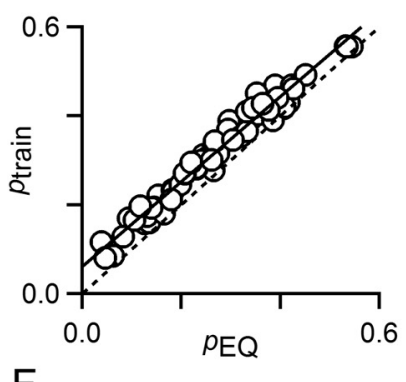

$\mathrm{F}$

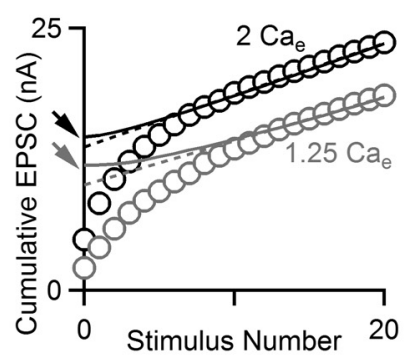

$\mathrm{H}$

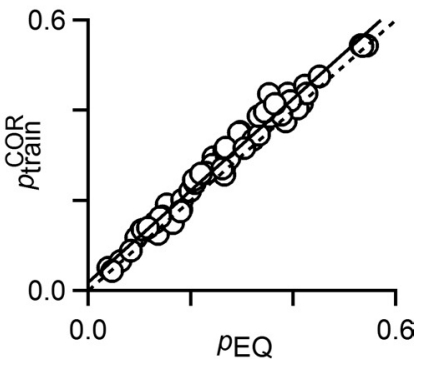

Figure 2. Techniques to quantify neurotransmitter release in response to a stimulus train. $\boldsymbol{A}$, Plot of EPSC amplitude versus stimulus number for a $100 \mathrm{~Hz}$ train in control conditions fitted with a single-exponential curve. $\boldsymbol{B}$, Plot of EPSC amplitude versus cumulative EPSC amplitude for the data in $\boldsymbol{A}$. A linear fit to the steepest range of the data gives an estimate of RRP size $\left(\mathrm{RRP}_{\mathrm{EQ}}\right) . C$, Plot of RRP train and RRP $\mathrm{EQ}_{\mathrm{Q}}$ values for cells in different $\mathrm{Ca}_{\mathrm{e}}(1,1.25,1.5,2,3$, and $4 \mathrm{~mm})$. $\boldsymbol{C}, \boldsymbol{D}, \boldsymbol{G}, \boldsymbol{H}, \mathrm{A}$ linear fit to the data (black line) and the unity line (dashed line) are shown. $\boldsymbol{D}$, Plot of $p_{\text {train }}$ and $p_{\mathrm{EQ}}$ values for the same cells as in $\boldsymbol{C}$. $\boldsymbol{E}$, Normalized EPSC amplitudes show recovery from depression after a single conditioning stimulus (gray circles) and after 40 stimuli at $100 \mathrm{~Hz}$ (black circles). Data were fit to a function of the form $(A+B \exp (-t / \tau))$, with parameters $\{A, B, t\}$ of $\left\{1,-0.466 \pm 4.73 \times 10^{-3}, 2.54 \pm .098 \mathrm{~s}\right\}$ following 1 conditioning stimulus and $\{1,-0.848 \pm 0.011,2.47 \pm .146 \mathrm{~s}\}$ following a train. $\boldsymbol{F}$, Comparison of RRP $_{\text {train }}$ (dashed lines) and corrected RRP ${ }_{\text {train, }}$ or $\mathrm{RRP}_{\text {train }}^{\mathrm{COR}}$ (solid lines) methods for measuring RRP.RRP $\mathrm{RPR}_{\text {train }}$ is indicated for $2 \mathrm{~mm} \mathrm{Ca}_{\mathrm{e}}$ (black arrow) and for $1.25 \mathrm{~mm} \mathrm{Ca}_{\mathrm{e}}$ (gray arrow). G, Plot of $\mathrm{RRP}_{\text {train }}^{\mathrm{COR}}$ versus $\mathrm{RRP}_{\mathrm{EQ}}$ and $(\boldsymbol{H})$ corrected $p_{\text {train }}\left(p_{\text {train }}^{\mathrm{COR}}\right)$ versus $p_{\mathrm{EQ}}$ for cells in different $C \mathrm{a}_{\mathrm{e}}$.

to the low availability of empty release sites. Late in the train, when the cumulative EPSC has reached a linear regime (constant EPSC amplitude), there should be more empty sites and replenishment should be more pronounced. A second possibility is that

A

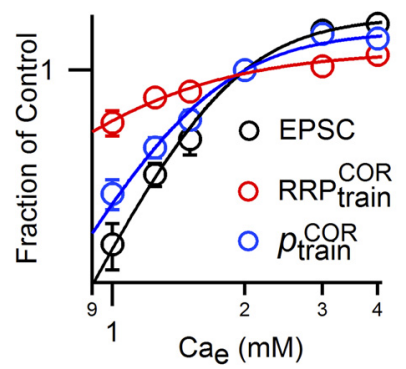

C

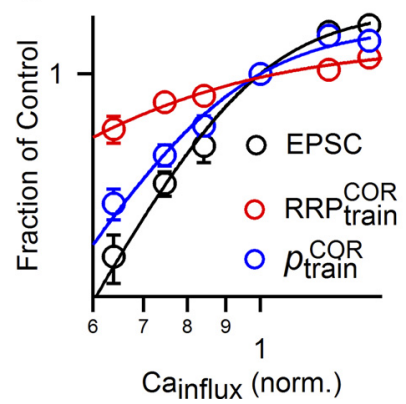

B

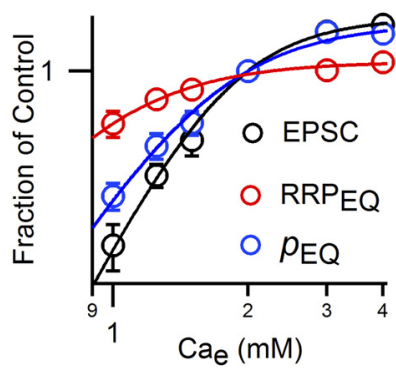

D

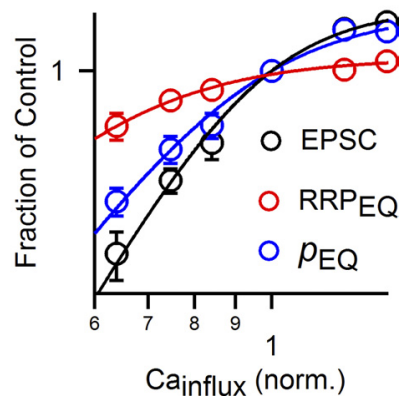

Figure 3. Contributions of effective RRP size to the calcium dependence of release. $A$, Plot of EPSC size, $\mathrm{RRP}_{\text {train }}^{\mathrm{COR}}$ and $p_{\text {train }}^{\mathrm{COR}}$ (normalized to values in $2 \mathrm{~mm} \mathrm{Ca}_{\mathrm{e}}$ ) versus $\mathrm{Ca}_{\mathrm{e}} . \boldsymbol{B}$, Plot of EPSC, $p_{\mathrm{EQ},}$ and RRP (normalized to values in $2 \mathrm{~mm} \mathrm{Ca}_{\mathrm{e}}$ ) versus $\mathrm{Ca}_{\mathrm{e}}$. Plots in $\boldsymbol{C}$ and $\boldsymbol{D}$ are similar to plots in $\boldsymbol{A}$ and $\boldsymbol{B}$, but values are plotted versus calcium influx $\left(\mathrm{Ca}_{\mathrm{influx}}\right)$. Relationship between $\mathrm{Ca}_{\mathrm{e}}$ and $\mathrm{Ca}_{\text {influx }}$ from Schneggenburger et al., 1999. All plots show data for 1, 1.25, 1.5, 2, 3, and $4 \mathrm{~mm}$ $\mathrm{Ca}_{\mathrm{e}} \cdot n \geq 5$ cells per $\mathrm{Ca}_{\mathrm{e}}$ value.

the time course of recovery from depression is accelerated late in the train as a result of calcium-dependent recovery from depression, which has been described at a variety of synapses (Dittman and Regehr, 1998; Stevens and Wesseling, 1998; Wang and Kaczmarek, 1998; Zucker and Regehr, 2002) and has been shown to be regulated by the calcium-binding protein calmodulin at this synapse (Sakaba and Neher, 2001a). To test for these two possibilities we compared recovery from depression following a single conditioning pulse with recovery from depression after a 40pulse train at $100 \mathrm{~Hz}$ (Fig. 2E). We found that at the end of the train there was more depression and the magnitude of recovery was larger than that observed after a single conditioning pulse; however, the time course of recovery was about the same, with a time constant of $\sim 2.5 \mathrm{~s}$ for both stimulus patterns. This suggests that it is possible to correct for differences in recovery from depression simply by taking into account the extent to which the RRP has been depleted. By performing such corrections we obtained a refined estimate of $\mathrm{RRP}_{\text {train }}$ that is corrected for differential recovery from depression, $\mathrm{RRP}_{\text {train }}^{\mathrm{COR}}$ (Fig. $2 F$, curves, see Materials and Methods). A plot of $\mathrm{RRP}_{\text {train }}^{\mathrm{COR}}$ versus $\mathrm{RRP}_{\mathrm{EQ}}$ shows considerably improved agreement (Fig. $2 G$, solid line, $m=0.881$, $b=0.284 \mathrm{nA}$ ) as does a plot of $p_{\text {train }}^{\mathrm{COR}}$ versus $p_{\mathrm{EQ}}$ for the same cells seen in Figure 2, $C$ and $D$, show (Fig. $2 H$, solid line, $m=1.02, b=$ $0.018)$. It should be noted that because the correction of $\mathrm{RRP}_{\text {train }}$ is larger when initial $p$ is smaller, the correction decreases our estimates of the size of changes in RRP. It also brings $\mathrm{RRP}_{\text {train }}^{\mathrm{COR}}$ and $\mathrm{RRP}_{\mathrm{EQ}}$ into close agreement. The close agreement of the two methods suggests that they provide an excellent estimate of RRP size and $p$. We will therefore use these two methods to quantify changes in RRP and $p$ in all subsequent figures.

We also went on to examine recovery from depression after a 40-pulse train in $1.25 \mathrm{mM} \mathrm{Ca}_{\mathrm{e}}$, and found that recovery from 
A
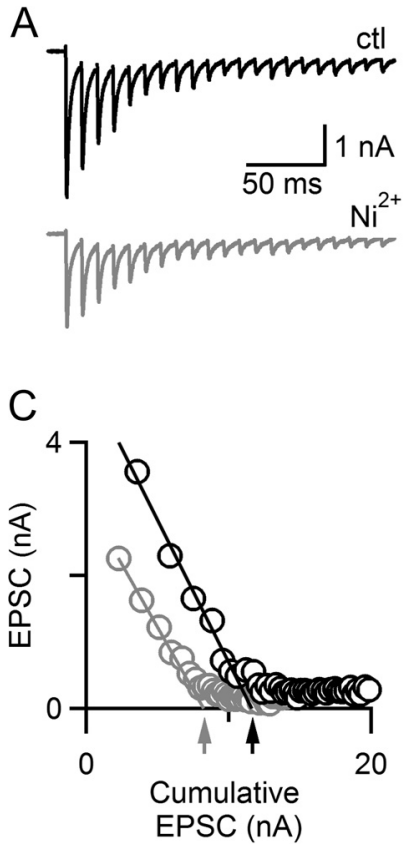

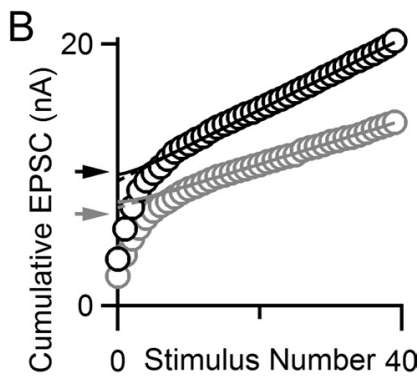

D

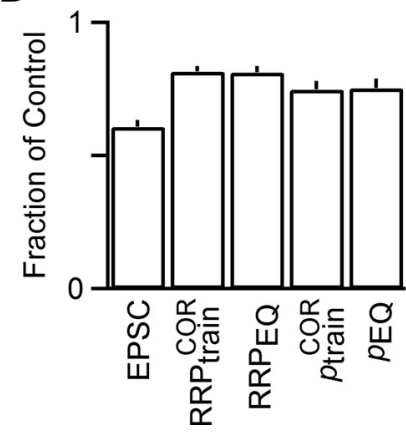

Figure 4. Nickel, a blocker of R-type VGCCs, reduces synaptic transmission through changes in $p$ and effective RRP. $A$, Example of postsynaptic responses to $100 \mathrm{~Hz}$ stimulus trains in control conditions (black) and Ni ${ }^{2+}$ (gray). B, A comparison of cumulative EPSCs reveals that $\mathrm{RRP}_{\text {train }}^{\mathrm{COR}}$ is reduced upon application of nickel chloride. Black circles indicate control conditions; gray circles indicate $\mathrm{Ni}^{2+}$. Arrows indicate $\mathrm{RRP}_{\text {train }}^{\mathrm{COR}}$. C, Plot of EPSC amplitude versus cumulative EPSC amplitude for the same data reveals that $\operatorname{RRP}_{\mathrm{EQ}}$ is also reduced in nickel chloride. Black circles indicate control conditions; gray circles indicate $\mathrm{Ni}^{2+}$. Arrows indicate $\mathrm{RRP}_{\mathrm{EO}}$. D, Summary of the effect of $\mathrm{Ni}^{2+}$ on the properties of synaptic transmission $(n=8)$.

depression was approximated by an exponential with a time constant of $3.5 \mathrm{~s}(n=4$ cells, data not shown). This is slightly longer than the time constant measured at $2 \mathrm{~mm} \mathrm{Ca}$. and is consistent with calcium slightly accelerating recovery from depression. It should be noted, however, that the correction method we introduced in Figure 2 provides a correction appropriate for each train that does not assume anything about the time constant of recovery from depression. Thus, small differences in recovery kinetics will be accounted for, and will not contribute to the observed changes in $\mathrm{RRP}_{\text {train }}^{\mathrm{COR}}$. Moreover, the replenishment is insufficient to account for calcium-dependent differences in $\mathrm{RRP}_{\mathrm{EQ}}$.

Having refined our methods of quantifying the RRP, we went on to determine whether the calcium dependence of effective RRP size contributes to the observed calcium dependence of the EPSC amplitude. Plots of the EPSC, RRP, and $p$ normalized to the value in $2 \mathrm{mM} \mathrm{Ca}_{\mathrm{e}}$ were made (Fig. $3 A, B$ ). Fits to the Hill equation revealed that the EPSC amplitude is steeply dependent on $\mathrm{Ca}_{\mathrm{e}}$ (Hill coefficient $\left.(n)=3.6, \mathrm{EC}_{50}\left(\mathrm{Ca}_{1 / 2}\right)=1.78 \mathrm{mM}\right)$, the probability of release is less steeply $\mathrm{Ca}_{\mathrm{e}}$ dependent $\left(p_{\text {train }}^{\mathrm{COR}}: n=3.2, \mathrm{Ca}_{1 /}\right.$ $2=1.56 \mathrm{mM}$ and $\left.p_{\mathrm{EQ}}: n=3.0, \mathrm{Ca}_{1 / 2}=1.66 \mathrm{mM}\right)$, as is the RRP ( $\operatorname{RRP}_{\text {train }}^{\mathrm{COR}}: n=2.0, \mathrm{Ca}_{1 / 2}=0.98 \mathrm{mM}$ and $\mathrm{RRP}_{\mathrm{EQ}}: n=2.7, \mathrm{Ca}_{1 / 2}=$ $0.92 \mathrm{mM}$ ). These findings suggest that the $\mathrm{Ca}_{\mathrm{e}}$ dependence of EPSC amplitude does not arise solely from $p$; the $\mathrm{Ca}_{\mathrm{e}}$ dependence of the RRP also contributes. It also appears that the RRP size saturates at lower values of $\mathrm{Ca}_{\mathrm{e}}$ than does the EPSC or $p$.

Calcium influx $\left(\mathrm{Ca}_{\text {influx }}\right)$ is not linearly related to $\mathrm{Ca}_{\mathrm{e}}$. To determine how EPSC amplitude, $p$, and RRP depend upon the $\mathrm{Ca}_{\text {influx }}$, we used the previously characterized relationship between $\mathrm{Ca}_{\mathrm{e}}$ and $\mathrm{Ca}_{\text {influx }}$ at this synapse (Schneggenburger et al., 1999) as follows:
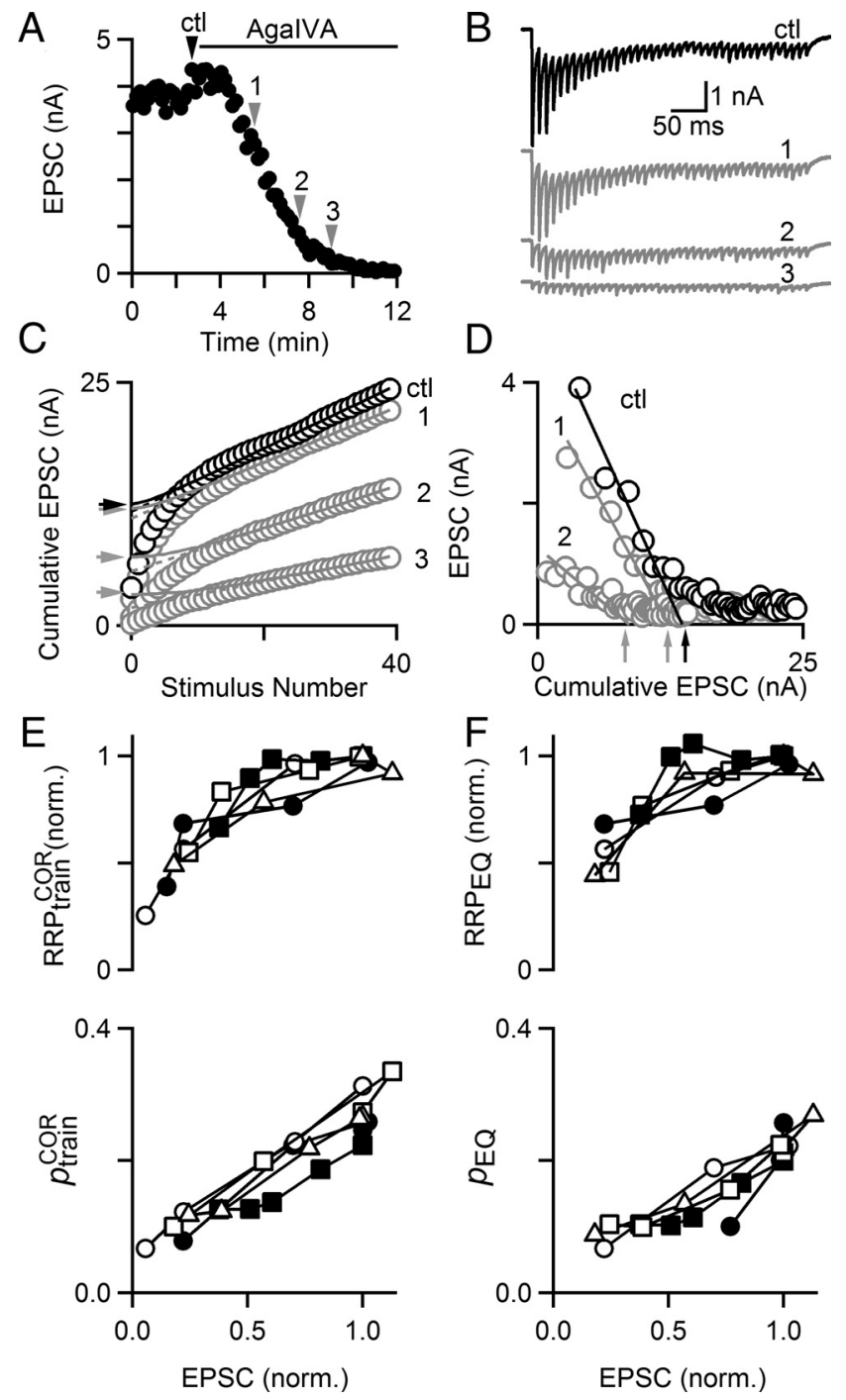

Figure 5. Inhibiting calcium entry through P-type VGCCs reduces synaptic strength through changes in $p$ and effective RRP. A, Application of the selective P/Q-type calcium channel antagonist $\omega$-agatoxin IVA (50 nm) potently inhibits EPSC amplitude. In this example cell, $100 \mathrm{~Hz}$ trains were delivered once in control conditions (black arrow) and three times during wash-in of $\omega$-agatoxin IVA (AgalVA, gray arrows). B, Postsynaptic responses in an example cell to a $100 \mathrm{~Hz}$ train in control conditions (black trace) and during submaximal application (gray traces). Times at which trains were delivered are indicated by arrows in $A$. C, Cumulative EPSC plots for the same example cell indicate that $\mathrm{RRP}_{\text {train }}^{\mathrm{COR}}$ is reduced by AgalVA. Arrows indicate $\mathrm{RRP}_{\text {train }}^{\mathrm{COR}} \cdot \boldsymbol{D}$, Plots of peak EPSC amplitude versus cumulative EPSC indicate that RRP ${ }_{E Q}$ is reduced by AgalVA. Arrows indicate $\mathrm{RRP}_{\mathrm{EQ}}$. $\boldsymbol{E}$, Plots of $\mathrm{RRP}_{\text {train }}^{\mathrm{COR}}$ normalized to control value (top) and $p_{\text {train }}^{\mathrm{COR}}$ (bottom) and $(\boldsymbol{F}) \operatorname{RRP}_{\mathrm{EQ}}$ normalized to control value (top) and $p_{\mathrm{EQ}}$ (bottom) $(\boldsymbol{F})$ as a function of EPSC amplitude. Each cell has a unique marker to indicate subsequent trains.

$$
\frac{J_{C a e, x}}{J_{C a e, 2 m M}}=\left(\frac{C a_{e, x}}{C a_{e, x}+E C_{50}}\right) \div\left(\frac{C a_{e, 2 m M}}{C a_{e, 2 m M}+E C_{50}}\right)
$$

Here, $J_{C a e, x}=$ flux of calcium ions into the presynaptic terminal at $x \mathrm{~mm} \mathrm{Ca}_{\mathrm{e}}, J_{C a e, 2 m M}=$ flux of calcium ions into the terminal at $2 \mathrm{mM} \mathrm{Ca}_{\mathrm{e}}$, and $\mathrm{EC}_{50}=2.6 \mathrm{~mm}$ (Schneggenburger et al., 1999). Plots of the EPSC, RRP, and $p$ normalized to $2 \mathrm{mM} \mathrm{Ca}_{\mathrm{e}}$ are shown versus estimated calcium influx $\left(\mathrm{Ca}_{\text {influx }}\right)$ (Fig. $\left.3 C, D\right)$. Fits to the Hill equation revealed that the EPSC amplitude is very steeply dependent on $\mathrm{Ca}_{\text {influx }}$ (Hill coefficient $(n)=5.6, \mathrm{Ca}_{1 / 2}=0.96$ ), the probability of release is less dependent on $\mathrm{Ca}_{\text {influx }}\left(p_{\text {train }}^{\mathrm{COR}}: n=\right.$ 
A

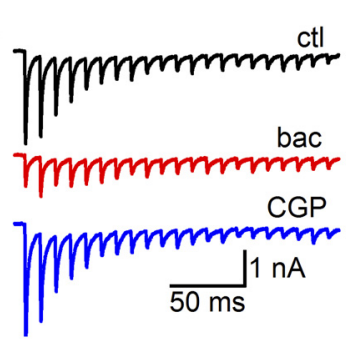

$B$
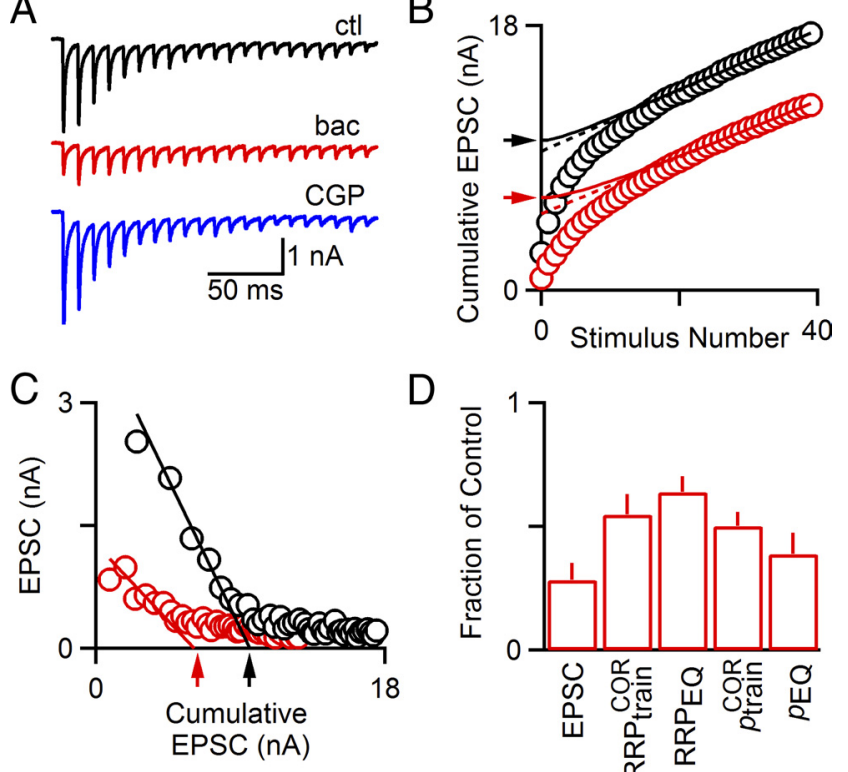

Figure 6. $\mathrm{GABA}_{B}$ receptors modulate synaptic transmission through changes in $p$ and effective RRP. $A$, Postsynaptic responses to a $100 \mathrm{~Hz}$ stimulus train in control conditions (black), in $100 \mu \mathrm{m}$ baclofen (bac; red), and in $20 \mu \mathrm{M}$ (GP 55845 (CGP; blue). B, Plot of cumulative EPSC versus stimulus number for example cell in control (black circles) and baclofen (red circles) indicates that $\mathrm{RRP}_{\text {train }}^{\mathrm{COR}}$ is reduced in baclofen. $\mathrm{RRP}_{\text {train }}^{\mathrm{COR}}$ is indicated by arrows. C, Plot of EPSC amplitude versus cumulative EPSC amplitude for the same data reveals that $R_{R P}$ is also reduced in baclofen. $\mathrm{RRP}_{\mathrm{EQ}}$ is indicated by arrows. $\boldsymbol{D}$, Summary of the effects of baclofen on properties of synaptic transmission $(n=9)$.

4.9, $\mathrm{Ca}_{1 / 2}=0.88$ and $p_{\mathrm{EQ}}: n=4.4, \mathrm{Ca}_{1 / 2}=0.93 \mathrm{mM}$ ), as is the RRP $\left(\mathrm{RRP}_{\text {train }}^{\mathrm{COR}}: n=2.7, \mathrm{Ca}_{1 / 2}=0.66\right.$ and $\mathrm{RRP}_{\mathrm{EQ}}: n=3.8, \mathrm{Ca}_{1 / 2}=$ $0.61)$. Thus we find that the same qualitative trends hold for the $\mathrm{Ca}_{\text {influx }}$ dependence of EPSC, $p$, and RRP, as for the $\mathrm{Ca}_{\mathrm{e}}$ dependence of these values, and the very steep $\mathrm{Ca}_{\text {influx }}$ dependence of EPSC amplitude arises in part from the $\mathrm{Ca}_{\text {influx }}$ dependence of the RRP.

The previous experiments suggest that the extent of action potential-evoked calcium influx through presynaptic VGCCs influences the effective size of the RRP, and therefore the strength of synaptic transmission. We tested the role of R-type calcium channels using $100 \mu \mathrm{M} \mathrm{Ni}^{2+}$, which blocks R-type calcium channels (Soong et al., 1993; Schneider et al., 1994; Zamponi et al., 1996) and reduces neurotransmitter release at the calyx of Held (Wu et al., 1998, 1999). The wash-in of $\mathrm{Ni}^{2+}$ reduced synaptic strength to $60.9 \pm 2.6 \%$ of control $(p<0.001)$, and reduced both RRP and $p$ (Fig. $4 A-C$ ). Both estimates of RRP size were reduced in nickel; $\mathrm{RRP}_{\text {train }}^{\mathrm{COR}}=81.6 \pm 2.1 \%$ of control $(p<0.001)$ and $\mathrm{RRP}_{\mathrm{EQ}}=$ $81.2 \pm 2.3 \%$ of control $(p<0.01)$. Estimates of $p$ were reduced as well; $p_{\text {train }}^{\mathrm{COR}}=74.8 \pm 3.1 \%$ of control $(p<0.001)$ and $p_{\mathrm{EQ}}=$ $75.3 \pm 3.5 \%(p<0.001)$. Thus, as with alterations in external calcium, decreases in RRP contribute to decreases in EPSC amplitude.

Previous studies have shown that P-type calcium channels are the primary source of calcium that drives neurotransmitter release at the calyx of Held (Iwasaki and Takahashi, 1998). We therefore used the selective P-type calcium channel antagonist $\omega$-agatoxin IVA (AgaIVA) to study synaptic transmission (Fig. 5). AgaIVA strongly decreased the EPSC amplitude, and once the steady-state response to AgaIVA had been attained, $p$ was so low $(<0.1)$ that it was impractical to deplete the RRP with a short train stimulus. We therefore delivered trains during the wash-in of AgaIVA, as indicated by the gray arrows in Figure $5 A$. The size
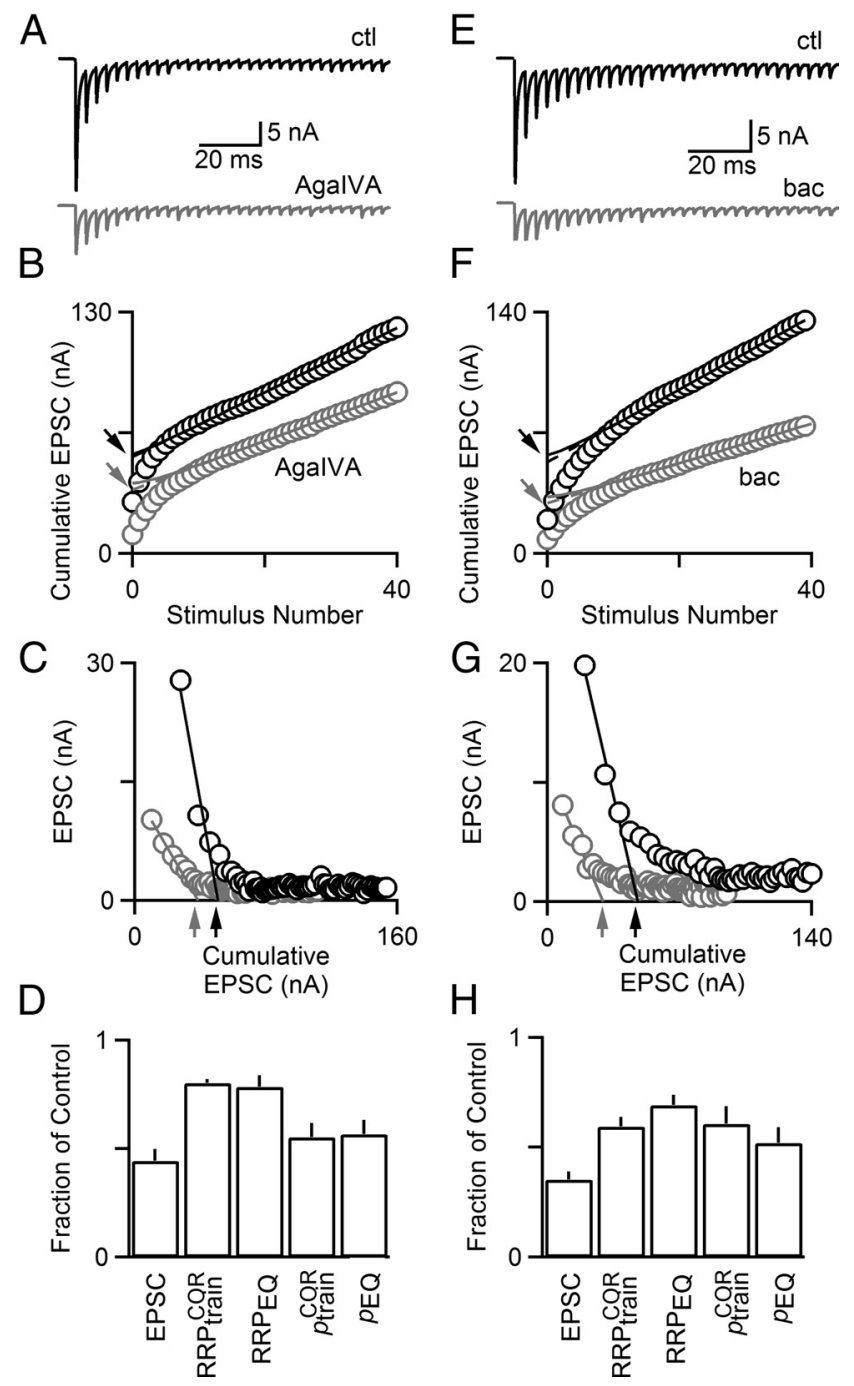

Figure 7. The size of the effective RRP is regulated by changes in presynaptic calcium influx for $300 \mathrm{~Hz}$ trains at near-physiological temperature. A, Postsynaptic responses of an example cell to a $300 \mathrm{~Hz}$ stimulus train delivered in control conditions and in AgalVA. B, Cumulative EPSC in an example cell in control conditions (black circles) and in AgalVA (gray circles) for the response shown in $\boldsymbol{A}$. The value of $\mathrm{RRP}_{\text {train }}^{\mathrm{COR}}$ is reduced (black vs gray arrows). $\boldsymbol{C}$, Plot of EPSC amplitude versus cumulative EPSC for the same example cell. Agatoxin (gray circles) reduces $\mathrm{RRP}_{\mathrm{EQ}}$ (gray vs black arrows). D, Summary of changes to EPSC amplitude, $\mathrm{RRP}_{\text {train }}^{\mathrm{COR}} \mathrm{RRP}_{\mathrm{EQ}}$ $p_{\text {train }}^{\mathrm{COR}}$ and $p_{\mathrm{EQ}}(n=4)$. $\boldsymbol{E}$, Postsynaptic responses of an example cell to a $300 \mathrm{~Hz}$ stimulus train delivered in control conditions and in baclofen $(100 \mu \mathrm{M}) . \boldsymbol{F}$, Cumulative EPSC in an example cell in control conditions (black circles) and in baclofen (gray circles) for a $300 \mathrm{~Hz}$ train delivered at $35^{\circ} \mathrm{C}$. The value of $\mathrm{RRP}_{\text {train }}^{\mathrm{COR}}$ is reduced (gray vs black arrows). G, Plot of EPSC amplitude versus cumulative EPSC for the same example cell. Baclofen (gray circles) reduces RRP EO $_{\text {(gray vs black }}$ arrows). $\boldsymbol{H}$, Summary of changes to EPSC amplitude, $\mathrm{RRP}_{\text {train }}^{\mathrm{COR}} \operatorname{RRP}_{\mathrm{E} e^{\prime}}, p_{\text {train }}^{\mathrm{COR}}$ and $p_{\mathrm{EQ} .}(n=5)$.

of the first EPSC decreased as AgaIVA took effect and the number of stimuli required to deplete the RRP increased, as shown in a representative experiment (Fig. 5B). Plots of the cumulative EPSC revealed that $\mathrm{RRP}_{\text {train }}^{\mathrm{COR}}$ (Fig. $5 C$ ) and $\mathrm{RRP}_{\mathrm{EQ}}$ (Fig. 5D) had been significantly reduced in AgaIVA. Summary data shows that the reduction of EPSC amplitude was accompanied by more modest decreases in both measures of RRP size, $\mathrm{RRP}_{\text {train }}^{\mathrm{COR}}$ and $\mathrm{RRP}_{\mathrm{EQ}}$, and of $p$, $p_{\text {train }}^{\mathrm{COR}}$ and $p_{\mathrm{EQ}}$ (Fig. $\left.5 E, F\right)$. This manipulation strongly suggests that the number of vesicles liberated by a train depends on the extent of calcium influx through presynaptic VGCCs.

Numerous neuromodulators regulate synaptic transmission by modulating presynaptic VGCCs, and it has been assumed that such modulation only reflects alterations in $p$ (Zucker and 
A

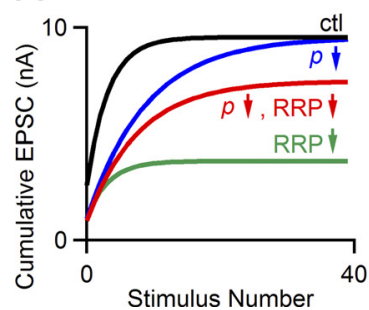

$B$

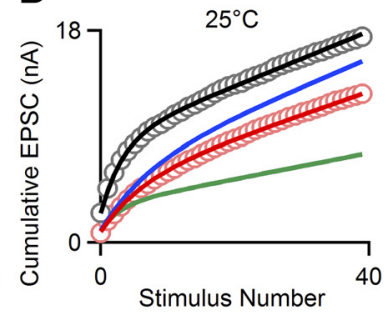

C

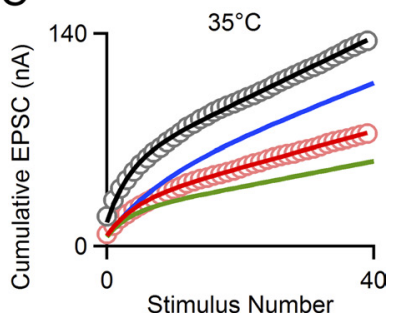

of control ( $p<0.001, n=5$ cells), with considerable effects on both measures of pool size $\left(\mathrm{RRP}_{\text {train }}^{\mathrm{COR}}: 59.4 \pm 4.3 \%\right.$ of control, $p<0.01$; $\mathrm{RRP}_{\mathrm{EQ}}: 69.3 \pm 4.6 \%$ of control, $p<0.01)$ and both measures of $p\left(p_{\text {train }}^{\mathrm{COR}}\right.$ : $60.7 \pm 8.0 \%$ of control, $p<0.01 ; \mathrm{p}_{\mathrm{EQ}}$ : $52.1 \pm 7.1 \%$ of control, $p<0.01)$. These experiments suggest that presynaptic calcium influx regulates the effective size of the RRP under physiological temperature and firing frequencies.

A simple model (see Materials and Methods) was used to illustrate the consequences of changing synaptic strength through changes in $p$ versus changes in effective RRP (Fig. 8A-C). The differences are best illustrated by considering the case where there is no replenishment of the RRP such that once the RRP is depleted no neurotransmitter release occurs (Fig. 8A). Three cases are considered that all lead to the same decrease in the initial EPSC, but

Regehr, 2002). However, our results suggest that changes in calcium influx can also affect the size of the RRP. We therefore tested this possibility by studying synaptic $\mathrm{GABA}_{\mathrm{B}}$ receptor-mediated synaptic inhibition at the calyx of Held synapse, which has been shown to be mediated by direct modulation of presynaptic VGCCs, with no significant downstream effects on vesicular release (Takahashi et al., 1998). We found that the $\mathrm{GABA}_{\mathrm{B}}$ receptor agonist baclofen $(100 \mu \mathrm{M})$ strongly inhibited synaptic strength at this synapse, which was reversed with the $\mathrm{GABA}_{\mathrm{B}}$ receptor antagonist CGP $55845(20 \mu \mathrm{M})$. Baclofen caused the synapse to facilitate, unlike in control conditions and in CGP 55845, and depletion of the RRP required more stimuli (Fig. 6A). In both control conditions and in baclofen, 40 stimuli were sufficient to deplete the RRP. In a representative experiment, we found that baclofen decreased both $\mathrm{RRP}_{\text {train }}^{\mathrm{COR}}$ (Fig. 6B) and $\mathrm{RRP} \mathrm{EQ}_{\mathrm{EQ}}$ (Fig. 6C). Baclofen reduced EPSC amplitudes to an average of $28.4 \pm 6.9 \%$ of control $(p<0.01)$, with intermediate effects on $\mathrm{RRP}_{\text {train }}^{\mathrm{COR}}$ $(54.8 \pm 8.2 \%$ of control, $p<0.01), \mathrm{RRP}_{\mathrm{EQ}}(63.9 \pm 6.3 \%$ of control, $p<0.05), p_{\text {train }}^{\mathrm{COR}}(50.1 \pm 5.7 \%$ of control, $p<0.001)$, and $p_{\mathrm{EQ}}(38.8 \pm 8.6 \%$ of control, $p<0.01)$ (summary in Fig. $6 D ; n=$ $9)$. This indicates that neuromodulators that act by regulating presynaptic VGCCs can affect synaptic transmission by modulating both $p$ and effective RRP size.

To test whether regulation of effective RRP size might be physiologically relevant, we repeated experiments at nearphysiological temperature $\left(35^{\circ} \mathrm{C}\right)$ with higher frequency $(300$ $\mathrm{Hz}$ ) trains. We measured postsynaptic responses in control conditions and in AgaIVA (example cell, Fig. 7A). Submaximal block of P-type VGCCs reduced both $\mathrm{RRP}_{\text {train }}^{\mathrm{COR}}$ (Fig. $7 B$ ) and $\mathrm{RRP}_{\mathrm{EQ}}$ (Fig. 7C). We restricted our analysis to trials in which the EPSC amplitude was moderately reduced $(44.3 \pm 5.5 \%$ of control, $p<$ $0.01, n=4$ cells) and found that as for room temperature experiments the blockade of P-type calcium channels reduced both the pool size $\left(\mathrm{RRP}_{\text {train }}^{\mathrm{COR}}: 80.2 \pm 1.8 \%\right.$ of control, $p<0.01$; $\mathrm{RRP}_{\mathrm{EQ}}$ : $78.5 \pm 5.4 \%$ of control, $p<0.01)$ and $p$ ( $p_{\text {train }}^{\mathrm{COR}}: 55.2 \pm 6.5 \%$ of control, $p<0.05 ; p_{\mathrm{EQ}}: 56.6 \pm 6.5 \%$ of control, $\left.p<0.01\right)$. This suggests that changes in effective pool size collaborate with changes in $p$ to produce the full effect of AgaIVA on synaptic transmission for higher frequency trains at $35^{\circ} \mathrm{C}$. We also tested the effect of activating presynaptic $\mathrm{GABA}_{\mathrm{B}}$ receptors (Fig. $7 \mathrm{E}-\mathrm{H}$ ) and found that the EPSC amplitude was reduced to $35.3 \pm 3.7 \%$ one does so by decreasing $p$, another by decreasing the effective RRP, and the third by small decreases in both $p$ and effective RRP. If synaptic strength is altered by reducing $p$, then it takes longer for repeated stimulation to deplete the RRP, but the total neurotransmitter release evoked by the train is unchanged (Fig. $8 \mathrm{~A}$, blue line). In contrast, reduction of the effective RRP size without altering $p$ reduces the overall neurotransmitter released by a train without altering the short-term plasticity (Fig. $8 A$, green line). If the both $p$ and effective RRP are decreased, as we have found to be the case at the calyx of Held, the cumulative EPSC is both smaller in final amplitude and requires more stimuli to reach depletion (Fig. $8 A$, red line).

In the realistic case, replenishment of the RRP must also be considered. We used the same model to evaluate the effect of $\mathrm{GABA}_{\mathrm{B}}$ activation on the cumulative EPSCs for two example experiments at $25^{\circ} \mathrm{C}$ (Fig. $8 B$ ) and at $35^{\circ} \mathrm{C}$ (Fig. $8 \mathrm{C}$ ), but in these simulations we also included replenishment of the RRP. The model takes into account the observation that replenishment is not constant but depends on the extent of depression (Fig. 2E). In the example at $25^{\circ} \mathrm{C}$, for the best approximations to the experimental data, baclofen reduced RRP and $p$ to 0.77 and 0.47 of control values, respectively, without decreasing the rate of replenishment (Fig. $8 B$, red line). Similarly at $35^{\circ} \mathrm{C}$ the best approximation was achieved by fractionally reducing the RRP and $p$, respectively, to 0.57 and 0.78 of control values, without altering replenishment (Fig. 8C, red line). In both cases, changes in $\mathrm{p}$ alone (blue lines) or in RRP alone (green lines), did not adequately describe the observed data.

The implication is that modulation of the effective RRP can change the total charge transfer in response to a train or rapid burst of presynaptic activity, which a change in only $p$ would not produce. Release of a neuromodulator could therefore affect the ability of a postsynaptic cell to follow high-frequency stimuli, which would be of great importance for a high-frequency, highfidelity synapse such as the calyx of Held.

\section{Discussion}

Our main finding is that in addition to changing $p$, alterations in presynaptic calcium influx change the effective RRP size. Thus, the calcium dependence of neurotransmitter release is determined by the combined calcium dependencies of $p$ and the effec- 
tive size of the RRP. These findings represent an advance in our understanding of the mechanisms controlling neurotransmitter release, and they establish that neuromodulators that change calcium entry can also change the size of the RRP, which has important functional consequences.

\section{Multiple approaches indicate that calcium influx regulates the RRP}

Here, we study the regulation of vesicles that can be elicited by a train of action potentials. This population of vesicles is crucial to studies of synaptic transmission, and has been studied by others using electrophysiological and optical techniques (Schneggenburger et al., 1999; Moulder and Mennerick, 2005; Ariel and Ryan, 2010). We use two independent methods that rely on different assumptions to establish the calcium dependence of the effective size of the RRP. The RRP $P_{\text {train }}$ method assumes that high-frequency stimulation rapidly depletes the RRP, and that after depletion the remaining release is due to replenishment (Schneggenburger et al., 1999). By assuming replenishment is constant throughout the train the size of the RRP is determined from the cumulative EPSC amplitude. In contrast, the $\mathrm{RRP}_{\mathrm{EQ}}$ method focuses on the early EPSCs in a train, in a range during which their amplitudes decay with a single exponential time course. The reasoning is that the decrement in EPSC amplitudes is a consequence of depletion of the RRP, and they can be used to estimate the size of the RRP (Elmqvist and Quastel, 1965).

A key strength of using these two methods is that the differences in initial assumptions can allow us to draw stronger conclusions. For example, the $\mathrm{RRP}_{\mathrm{EQ}}$ method assumes constant $p$ during the first several EPSCs of the train, which could be problematic under low $p$ conditions when facilitation occurs early in the train, or if calcium channel inactivation during the train significantly affects $p$ (Cuttle et al., 1998; Forsythe et al., 1998). Conveniently, the $\mathrm{RRP}_{\text {train }}^{\mathrm{COR}}$ method (and the original $\mathrm{RRP}_{\text {train }}$ method) does not require constant $p$. The fact that our estimates of pool size change when both methods agree indicates that facilitation and calcium channel inactivation are unlikely to significantly affect our ability to measure the effective RRP.

These methods are expected to bracket the actual RRP, as described previously. Indeed, we found that our estimates of $\mathrm{RRP}_{\text {train }}$ were slightly smaller than our estimates of $\mathrm{RRP}_{\mathrm{EQ}}$. (Fig. 2). However, by determining the properties of recovery from depression early and late in the train we were able to correct for decreased recovery from depression early in the train, and found a remarkable agreement between $\mathrm{RRP}_{\text {train }}^{\mathrm{COR}}$ and $\mathrm{RRP}_{\mathrm{EQ}}$ (Fig. $2 F$ ). This agreement strengthens our confidence in our ability to quantify the effective RRP and detect changes in the size of the RRP.

We altered calcium influx in many different ways, and in all cases changes in effective RRP size contributed to changes in EPSC amplitude. Altering $\mathrm{Ca}_{\mathrm{e}}$ to reduce the influx per channel, blocking R-type VGCCs, and blocking a fraction of P/Q-type VGCCs all reduced $p$ and effective RRP size. For all manipulations the change in $p$ typically amounts to double the change in effective RRP size, suggesting that the calcium-dependent changes of RRP size is a general feature of transmitter release at this synapse.

The results shown here have important consequences for the power law dependence of release, which is typically attributed exclusively to the calcium dependence of $p$. Our results confirm that the majority of the calcium dependence of EPSC size at the calyx of Held arises from changes in $p$ (Fig. 3), but that changes in the size of the effective RRP may be an important determinant of action potential-evoked release. We posit that the calcium depen- dence of the size of the effective RRP should be considered in future studies of synaptic transmission.

\section{Possible mechanisms by which calcium influx regulates the RRP}

The findings presented here raise the question: What determines which vesicles belong to the effective RRP, and how is this regulated by calcium influx? Measures of the RRP that have been previously used, such as hypertonic sucrose application, presynaptic voltage steps, and calcium uncaging (Rosenmund and Stevens, 1996; Schneggenburger et al., 1999; Sakaba and Neher, 2001b) do not use physiological stimuli to deplete the RRP, in contrast to our methods. Measurement of the RRP with hypertonic sucrose application has been shown to be invariant with presynaptic calcium (Rosenmund and Stevens, 1996), while our measures of effective RRP size in this study are clearly calcium dependent. The main difference between these techniques is that action potential-evoked calcium influx is temporally and spatially constrained, such that action potentials only generate brief microdomains of high $\mathrm{Ca}^{2+}$ while the other stimuli either create prolonged $\mathrm{Ca}^{2+}$ signals or do not rely on calcium influx to cause release.

The extent of calcium microdomains cannot be measured directly, but modeling approaches suggest that single VGCCs can only affect release within about $50 \mathrm{~nm}$ (Fogelson and Zucker, 1985; Simon and Llinás, 1985). At the calyx of Held, clusters of VGCCs are responsible for the release of most vesicles (Borst and Sakmann, 1999) and can create calcium microdomains of a few hundred nanometers (Meinrenken et al., 2002). This raises the possibility that the distance between docked vesicles and VGCCs determines their inclusion in the effective RRP, which we define here as the vesicles that can be released by action potential stimuli. It is known that the distance between vesicles and presynaptic calcium channels varies, and this distance is crucial for determining whether action-potential-induced calcium entry can cause exocytosis (Fogelson and Zucker, 1985; Simon and Llinás, 1985; Augustine, 2001; Wadel et al., 2007). Many studies have suggested that vesicle positioning within calcium microdomains can lead to heterogeneous probabilities of release for individual vesicles (Pr) at the calyx of Held synapse (Sakaba and Neher, 2001b; Meinrenken et al., 2002) and other synapses (Cooper et al., 1996; Shahrezaei and Delaney, 2004; Beaumont et al., 2005). Some vesicles may be positioned sufficiently far away from presynaptic calcium channels that they never experience sufficient calcium concentrations for release under conditions of reduced calcium influx, and therefore are excluded from the effective RRP. It is also possible that heterogeneity of the molecular sensors responsible for molecular fusion could lead to the observed calcium dependence of the size of the effective RRP; however, it is unlikely to account for the majority of the effect at this synapse (Wadel et al., 2007).

\section{Functional implications of changes in calcium influx regulating the RRP}

The generalizability of this mechanism may have important physiological implications. At many different types of synapses, neuromodulators regulate presynaptic VGCCs to decrease presynaptic calcium influx. It had previously been assumed that such neuromodulation alters transmission exclusively by changing $p$ (Zucker and Regehr, 2002). We find, however, that $\mathrm{GABA}_{\mathrm{B}}$ receptor activation at the calyx of Held does not reduce neurotransmitter release exclusively by regulating $p$; instead, the effective RRP size is also regulated (Fig. 6). Moreover the relative contributions of changes in $p$ and changes in RRP are similar to those 
observed when calcium entry is regulated. These effects persist at near-physiological temperature for faster trains (Fig. 7).

We used a simple model to illustrate the consequences of changing synaptic strength through changes in $p$ versus changes in effective RRP (Fig. $8 A-C$ ). The differences between changes in $p$ and RRP are best illustrated by considering the case where there is no replenishment of the RRP, and once the RRP is depleted no neurotransmitter release occurs (Fig. $8 A$ ). If synaptic strength is altered by reducing $p$, then it takes longer for repeated stimulation to deplete the RRP, but the overall release evoked by the train is unchanged. In contrast, reduction of the effective RRP size reduces the overall neurotransmitter released by a train. The same holds true when replenishment is added into the simulation (Fig. $8 B, C$ ). The data presented in this paper suggest that both processes occur and that a change in $p$ accounts for approximately two-thirds of the change in EPSC size and a change in effective RRP for the remaining one-third (Fig. $8 A-C$, red lines).

The implication is that modulation of the effective RRP can change the total charge transfer in response to a train or rapid burst of presynaptic activity, which a change in only $p$ would not produce. Release of a neuromodulator could therefore affect the ability of a postsynaptic cell to follow high-frequency stimuli, which would be of great importance for a high-frequency, highfidelity synapse such as the calyx of Held.

\section{References}

Ariel P, Ryan TA (2010) Optical mapping of release properties in synapses. Front Neural Circuits 4, pii: 18. CrossRef Medline

Augustine GJ (2001) How does calcium trigger neurotransmitter release? Curr Opin Neurobiol 11:320-326. CrossRef Medline

Beaumont V, Llobet A, Lagnado L (2005) Expansion of calcium microdomains regulates fast exocytosis at a ribbon synapse. Proc Natl Acad Sci U S A 102:10700-10705. CrossRef Medline

Borst JG, Sakmann B (1996) Calcium influx and transmitter release in a fast CNS synapse. Nature 383:431-434. CrossRef Medline

Borst JG, Sakmann B (1999) Effect of changes in action potential shape on calcium currents and transmitter release in a calyx-type synapse of the rat auditory brainstem. Philos Trans R Soc Lond B Biol Sci 354:347-355. CrossRef Medline

Cooper RL, Winslow JL, Govind CK, Atwood HL (1996) Synaptic structural complexity as a factor enhancing probability of calcium-mediated transmitter release. J Neurophysiol 75:2451-2466. Medline

Cuttle MF, Tsujimoto T, Forsythe ID, Takahashi T (1998) Facilitation of the presynaptic calcium current at an auditory synapse in rat brainstem. J Physiol 512:723-729. CrossRef Medline

Dittman JS, Regehr WG (1998) Calcium dependence and recovery kinetics of presynaptic depression at the climbing fiber to Purkinje cell synapse. J Neurosci 18:6147-6162. Medline

Dodge FA Jr, Rahamimoff R (1967) Co-operative action a calcium ions in transmitter release at the neuromuscular junction. J Physiol 193: 419-432. Medline

Elmqvist D, Quastel DM (1965) A quantitative study of end-plate potentials in isolated human muscle. J Physiol 178:505-529. Medline

Fogelson AL, Zucker RS (1985) Presynaptic calcium diffusion from various arrays of single channels. Implications for transmitter release and synaptic facilitation. Biophys J 48:1003-1017. CrossRef Medline

Forsythe ID, Tsujimoto T, Barnes-Davies M, Cuttle MF, Takahashi T (1998) Inactivation of presynaptic calcium current contributes to synaptic depression at a fast central synapse. Neuron 20:797-807. CrossRef Medline

Iwasaki S, Takahashi T (1998) Developmental changes in calcium channel types mediating synaptic transmission in rat auditory brainstem. J Physiol 509:419-423. CrossRef Medline

Jenkinson DH (1957) The nature of the antagonism between calcium and magnesium ions at the neuromuscular junction. J Physiol 138:434-444. Medline

Kushmerick C, Renden R, von Gersdorff H (2006) Physiological temperatures reduce the rate of vesicle pool depletion and short-term depression via an acceleration of vesicle recruitment. J Neurosci 26:1366-1377. CrossRef Medline
Lou X, Korogod N, Brose N, Schneggenburger R (2008) Phorbol esters modulate spontaneous and $\mathrm{Ca} 2+$-evoked transmitter release via acting on both Munc13 and protein kinase C. J Neurosci 28:8257-8267. CrossRef Medline

Meinrenken CJ, Borst JG, Sakmann B (2002) Calcium secretion coupling at calyx of held governed by nonuniform channel-vesicle topography. J Neurosci 22:1648-1667. Medline

Mintz IM, Sabatini BL, Regehr WG (1995) Calcium control of transmitter release at a cerebellar synapse. Neuron 15:675-688. CrossRef Medline

Moulder KL, Mennerick S (2005) Reluctant vesicles contribute to the total readily releasable pool in glutamatergic hippocampal neurons. J Neurosci 25:3842-3850. CrossRef Medline

Pan B, Zucker RS (2009) A general model of synaptic transmission and short-term plasticity. Neuron 62:539-554. CrossRef Medline

Rizzoli SO, Betz WJ (2005) Synaptic vesicle pools. Nat Rev Neurosci 6:5769. CrossRef Medline

Rosenmund C, Stevens CF (1996) Definition of the readily releasable pool of vesicles at hippocampal synapses. Neuron 16:1197-1207. CrossRef Medline

Sakaba T, Neher E (2001a) Calmodulin mediates rapid recruitment of fastreleasing synaptic vesicles at a calyx-type synapse. Neuron 32:1119-1131. CrossRef Medline

Sakaba T, Neher E (2001b) Quantitative relationship between transmitter release and calcium current at the calyx of held synapse. J Neurosci 21: 462-476. Medline

Schneggenburger R, Neher E (2000) Intracellular calcium dependence of transmitter release rates at a fast central synapse. Nature 406:889-893. CrossRef Medline

Schneggenburger R, Meyer AC, Neher E (1999) Released fraction and total size of a pool of immediately available transmitter quanta at a calyx synapse. Neuron 23:399-409. CrossRef Medline

Schneider T, Wei X, Olcese R, Costantin JL, Neely A, Palade P, Perez-Reyes E, Qin N, Zhou J, Crawford GD. (1994) Molecular analysis and functional expression of the human type E neuronal $\mathrm{Ca} 2+$ channel alpha 1 subunit. Receptors Channels 2:255-270. Medline

Shahrezaei V, Delaney KR (2004) Consequences of molecular-level $\mathrm{Ca} 2+$ channel and synaptic vesicle colocalization for the $\mathrm{Ca} 2+\mathrm{mi}-$ crodomain and neurotransmitter exocytosis: a Monte Carlo study. Biophys J 87:2352-2364. CrossRef Medline

Simon SM, Llinás RR (1985) Compartmentalization of the submembrane calcium activity during calcium influx and its significance in transmitter release. Biophys J 48:485-498. CrossRef Medline

Smith SJ, Augustine GJ, Charlton MP (1985) Transmission at voltageclamped giant synapse of the squid: evidence for cooperativity of presynaptic calcium action. Proc Natl Acad Sci U S A 82:622-625. CrossRef Medline

Soong TW, Stea A, Hodson CD, Dubel SJ, Vincent SR, Snutch TP (1993) Structure and functional expression of a member of the low voltageactivated calcium channel family. Science 260:1133-1136. CrossRef Medline

Stevens CF, Wesseling JF (1998) Activity-dependent modulation of the rate at which synaptic vesicles become available to undergo exocytosis. Neuron 21:415-424. CrossRef Medline

Stevens CF, Williams JH (2007) Discharge of the readily releasable pool with action potentials at hippocampal synapses. J Neurophysiol 98:3221-3229. CrossRef Medline

Takahashi T, Kajikawa Y, Tsujimoto T (1998). G-Protein-coupled modulation of presynaptic calcium currents and transmitter release by a GABAB receptor. J Neurosci 18:3138-3146. Medline

Taschenberger H, Scheuss V, Neher E (2005) Release kinetics, quantal parameters and their modulation during short-term depression at a developing synapse in the rat CNS. J Physiol 568:513-537. CrossRef Medline

Wadel K, Neher E, Sakaba T (2007) The coupling between synaptic vesicles and $\mathrm{Ca} 2+$ channels determines fast neurotransmitter release. Neuron 53:563-575. CrossRef Medline

Wang LY, Kaczmarek LK (1998) High-frequency firing helps replenish the readily releasable pool of synaptic vesicles. Nature 394:384-388. CrossRef Medline

Wu LG, Saggau P (1994) Pharmacological identification of two types of presynaptic voltage-dependent calcium channels at CA3-CA1 synapses of the hippocampus. J Neurosci 14:5613-5622. Medline

Wu LG, Borst JG, Sakmann B (1998) R-type Ca2 + currents evoke trans- 
mitter release at a rat central synapse. Proc Natl Acad Sci U S A 95: 4720-4725. CrossRef Medline

Wu LG, Westenbroek RE, Borst JG, Catterall WA, Sakmann B (1999) Calcium channel types with distinct presynaptic localization couple differentially to transmitter release in single calyx-type synapses. J Neurosci 19: 726-736. Medline
Zamponi GW, Bourinet E, Snutch TP (1996) Nickel block of a family of neuronal calcium channels: subtype- and subunit-dependent action at multiple sites. J Membr Biol 151:77-90. CrossRef Medline

Zucker RS, Regehr WG (2002) Short-term synaptic plasticity. Annu Rev Physiol 64:355-405. CrossRef Medline 